\title{
LEVEL OF PHYSICAL ACTIVITY AND ITS ASSOCIATION WITH HB LEVEL AMONG DPT
} STUDENTS

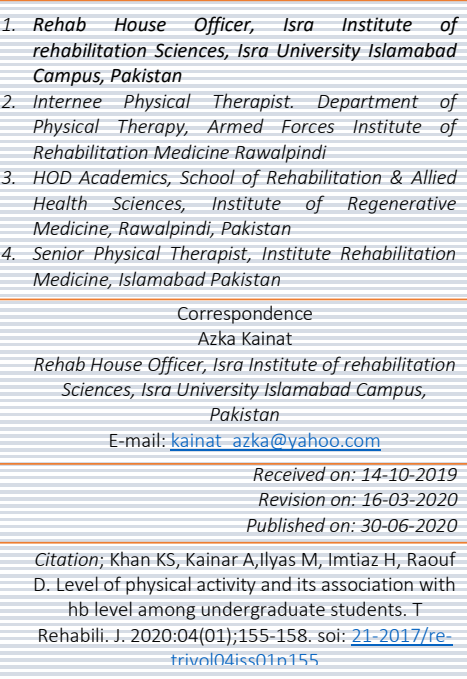

Khadija Shiraz Khan ${ }^{1}$ : Analysis \& interpretation of data, writing; Revised and accountable for all aspects

Azka Kainat ${ }^{1}$ : Conception \& Designing, Revised and accountable for all aspects

Mehwish llyas ${ }^{2}$ : Interpretation of data, writing; Revised and accountable for all aspects

Hamza Imtiaz: Interpretation of data, writing; Revised and accountable for all aspects

Danish Raouf ${ }^{3,4}$ : Interpretation of data, writing; Revised and accountable for all aspects

\section{ABSTRACT}

Objective: The objective of this study was to evaluate the level of physical activity and its association with hemoglobin level among undergraduate students. Method and materials: A cross-sectional study was conducted on undergraduate students of Isra Institute Rehabilitation Sciences, Isra University Islamabad. The undergraduate students between 1825 years were included in the study. The hemoglobin level was evaluated through the hemoglobin-meter and physical activity through the International Physical Activity Questionnaires IPAQ-SF-7. The Pearson product-moment correlation was used to find association between physical activity and hemoglobin level. Results: The mean age of study participants was $21.10 \pm 1.76$. Of the 400 participants, $22 \%$ participants had low level of physical activity, $46.25 \%$ participants had moderate level of physical activity and $31.75 \%$ participants had vigorous physical activity. The time spent in vigorous and moderate physical activity was significantly associated with the hemoglobin level $(p<0.05)$ and sitting was negatively correlated with $\mathrm{Hb}(p<0.05)$. Conclusion: It was concluded that that levels of physical activity was significantly associated with the hemoglobin level.

Keywords: Physical activity, hemoglobin, anemia.

\section{INTRODUCTION}

Physical activity is the skeletal muscles movements in the form of contraction and relaxation due to which energy is utilized. ${ }^{(1}$ It is categorized as low, moderate and high physical activity. The mild physical activity occurs when metabolic equivalent (METS) is 1.5 to 2.9 like slow pace walking, the moderate physical activity occurs about 3 to 5.9 METs as the brisk walking and the Vigorous physical activity is defined as METs more than $6 .^{2}$

Globally, the $4^{\text {th }}$ common leading cause of death is due to physical inactivity. ${ }^{3}$ According to $\mathrm{WHO}, 3.2$ million deaths per year occurs due to physical inactivity throughout the world. ${ }^{4}$ Overweight and obesity mainly occurs due to the physical inactivity. ${ }^{5}$ National health survey of Pakistan reported that $25 \%$ of population is overweight while $10 \%$ is obese. A total of $60 \%$ world's population is physically inactive or doing very little physical activity which is similar to the statistics of Pakistan and reported that majority of adults are physically inactive. ${ }^{6}$

Physical activity lowers the risk of establishing major cardiovascular diseases (CVD) and metabolic syndrome, obesity, osteoporosis, and muscular weakness. $^{7}$ Regular physical activity remains important in prevention of disorders of muscles and skeleton which includes mechanical low back pain, cervical and shoulder pain. ${ }^{8}$

The barriers to physical inactivity are lack of time due to hectic routine related to studies, parents prefer academic success compared to the exercise. ${ }^{3}$ Physical inactivity is a crucial risk factor for cardio-vascular disease, type 2 diabetes, and numerous forms of cancers. ${ }^{9}$ It also leads to premature deaths. ${ }^{10}$

The average hemoglobin value required for males is 14 to $18 \mathrm{~g} / \mathrm{dl}$ whereas that for females is 12 to 16 $\mathrm{g} / \mathrm{dl}$. The appropriate hemoglobin level $(\mathrm{Hb})$ is essential for the proper tissues oxygenation. ${ }^{11}$ According to Haas et al, the reduced work outcome is due to low $\mathrm{Hb}$ and reduction in oxygen transport. Iron deficiency anemia effect the capacity of activity performance and by improving iron status, human capital or work outcome can also be enhanced. $^{12}$ The causes of low $\mathrm{Hb}$ includes, malnourishment as a result of poor diet habits, worm infections, menarche, socio-demographic factors like age, gender, community status. ${ }^{13,14}$

Limited studies were available in Pakistan related to the association of $\mathrm{HB}$ with different levels of physical activities. The significance of healthy diet and sufficient degree of physical performance is well understood by medical students yet they do not pay attention to this fact. So it is difficult for them to make people aware about the benefits of physical activity. This study was conducted to explore the levels of physical activity and its association with HB levels among undergraduate students.

\section{METHODOLOGY}

A cross-sectional study was conducted on $n=400$ undergraduate students of Isra Institute Rehabilitation Sciences, Isra University Islamabad, after the approval from the Advanced Study \& Research Committee (ASRC) from December 2018 to February 2019. Written informed consent was 
obtained from the participants prior to data collection, after explaining the detail of study.

Participants fulfilling the eligibility criteria were recruited through purposive sampling technique, which were the undergraduate students (both male and female) of Isra University, Islamabad, among the age of 18 to 25 years while the students with fever, hemophilia, history of fracture<1-year, physical impairments and hepatitis $(B, C, D)$ were excluded from the study.

Furthermore, the demographic details were obtained from the study participants including age, gender, height and BMI. Hb was evaluated through hemoglobin-meter while IPAQ-SF-7 was used for the levels of physical activity (PA). The IPAQ-SF-7 is valid and a reliable tool. ${ }^{15}$ Hemoglobin was measured through hemoglobin meter (Inst-answer, LBM-01).

The numerical data was expressed as mean and standard deviation (SD), while percentages and frequencies were calculated for the categorical variables. As the data was normally distributed, so, Pearson Product-Moment Correlation was used to find the association between PA and $\mathrm{Hb}$ level. A pvalue $<0.05$ was considered statistically significant. The data was analysed through SPSS 21.

\begin{tabular}{llll}
\hline \hline RESULTS & & & \\
\hline The mean & age of study participants was \\
$21.10 \pm 1.76$. The general demographics of
\end{tabular}

participants of the study included age, height, weight and $\mathrm{Hb}$ levels was measured as shown in table 1. Furthermore, in this study 88 (22\%) participants had low level of physical activity while 185 (46.25\%) participants had moderate level of physical activity and 127 (31.75\%) participants had vigorous physical activity

Table 1: Descriptive Demographics Minimum Maximum Mean \pm Sd.Div

\begin{tabular}{cccc}
\hline Age in years & 18 & 24 & $21.10 \pm 1.76$ \\
\cline { 2 - 4 } Height in feet & 5.0 & 6.3 & $5.47 \pm 0.28$ \\
\cline { 2 - 4 } $\begin{array}{c}\text { Weight in kg } \\
\text { HB in g/dL }\end{array}$ & 65 & 95 & $59.15 \pm 10.76$ \\
\hline
\end{tabular}

The vigorous physical activities and time spent in vigorous activities was positively correlated with $\mathrm{HB}$ $(r=0.216, p=0.000$ and $r=0.192, p=0.000$ respectively). Furthermore, the moderate physical activities was also positively correlated with $\mathrm{HB}$ $(r=0.099, p=0.049)$ while time spent in moderate activities was not significantly associated with $\mathrm{HB}$ $(r=0.093, p=0.063)$. Moreover, walking and time spent in walking was also not significantly associated with HB. $(r=0.046, p=0.358$ and $r=0.042$, $p=0.401$ respectively). While sitting was negatively correlated with HB ( $r=-.107, p=.032)$. Additionally, IPAQ 7 total score was positively correlated with $\mathrm{HB}$ $(r=0.155, p=0.002)$. (Table 2$)$

Table 2: Correlation between PA \& Hb level

\begin{tabular}{|c|c|c|c|c|}
\hline & \multirow[t]{2}{*}{ Mean } & \multirow[t]{2}{*}{ SD } & \multicolumn{2}{|c|}{$\begin{array}{l}\text { HB Level in gldl } \\
(10.92 \pm 2.03)\end{array}$} \\
\hline & & & $r$ & $p$-value \\
\hline $\begin{array}{l}\text { During the last } 7 \text { days, on how many days did you do } \\
\text { vigorous physical activities? (days) }\end{array}$ & .75 & 1.60 & $0.216^{* *}$ & $0.000 * * *$ \\
\hline $\begin{array}{l}\text { How much time did you usually spend doing vigorous } \\
\text { physical activities on one of those days? (min.) }\end{array}$ & 16.73 & 43.55 & $0.192^{* *}$ & $0.000^{* * *}$ \\
\hline $\begin{array}{l}\text { During the last } 7 \text { days, on how many days did you do } \\
\text { moderate physical activities? (days) }\end{array}$ & 2.02 & 2.37 & $0.099^{*}$ & $0.049 * *$ \\
\hline $\begin{array}{l}\text { How much time did you usually spend doing moderate } \\
\text { physical activities on one of those days? (min.) }\end{array}$ & 30.30 & 61.74 & 0.093 & 0.063 \\
\hline $\begin{array}{l}\text { During the last } 7 \text { days, on how many days did you walk for } \\
\text { at least } 10 \text { minutes at a time? (days) }\end{array}$ & 5.43 & 2.09 & 0.046 & 0.358 \\
\hline $\begin{array}{l}\text { How much time did you usually spend walking on one of } \\
\text { those days? (min.) }\end{array}$ & 80.86 & 82.60 & 0.042 & 0.401 \\
\hline $\begin{array}{l}\text { During the last } 7 \text { days, how much time did you spend } \\
\text { sitting on a week day? (days) }\end{array}$ & 7.61 & 3.75 & $-0.107^{*}$ & $0.032 * *$ \\
\hline IPAQ7 Total Score & 113.73 & 88.95 & $0.155^{* *}$ & $0.002 * *$ \\
\hline
\end{tabular}

\section{DISCUSSION}

The objective of the study was to explore levels of physical activity and its relationship with hemoglobin $(\mathrm{Hb})$ level among students. In a current study low physical activity was observed in 88 (22\%) students while 185 (46.25\%) participants had moderate level of physical activity and 127 (31.75\%) participants had vigorous physical 
activity. According to a study conducted in Bangalore, India, on physical activity among medical undergraduates of 18 to 22 years of age, using International Physical Activity Questionnaire (IPAQ). High physical activity was present in $41.3 \%$ of the students while $43.2 \%$ have moderate physical activity and $15.4 \%$ of the students were having low levels of activities. ${ }^{16}$ Another study was conducted in Poland, to evaluate the physical activity in students of the medical university of Silesia, which demonstrated that $46 \%$ of the physical therapist had the vigorous level of physical activity, $54 \%$ had a moderate level of physical activity. ${ }^{17}$

Moreover, in this study it has been determined that the vigorous and high level of physical activity is significantly associated with hemoglobin level. This correlates with the previous study, in which it has been reported that if a person performs physical activity, it causes the muscles to manage with severe oxygen deficiency which leads the muscles to balance the need of $\mathrm{O} 2$ by having accessibility of oxygen. The muscles have the capability to cope with this oxygen deficiency so it combines very rapidly to develop oxy-hemoglobin. It leads to the increase in $\mathrm{HB}$ concentration and have better health outcomes as well. ${ }^{18,19}$ Also, many physiological responses can lead to the condition of hypoxia for example exercise. ${ }^{18}$ And hypoxia is deliberated to a greater extent by stimulation of the transcription factor which is sensitive to hypoxia. Endurance exercises trigger the hypoxia sensitive transcription factor. This element leads to the excess transportation of oxygen through blood via procedure like erythropoietin-mediated erythropoiesis. ${ }^{20}$

Moreover, increase in endurance exercises are connected with hemoglobin levels. It is also linked to the increase of the oxygen carrying capability of blood. $^{21}$ Furthermore, regular participation in moderate physical activity was also significantly associated with HB an level which also correlates with the previous study which stated that continuous and regular exercises of moderate intensity, aerobics and endurance exercises can improve the $\mathrm{Hb}$ levels. The endurance exercises helps to improves the growth hormone production through the hematopoiesis as well as enhance cytokines concentration which mature, proliferate and renew the blood stem cells. ${ }^{22}$ Moreover, according to some previous literature, it has been concluded that aerobic training can significantly improve the $\mathrm{Hb}$ level. ${ }^{23,24}$

Additionally, in a recent study it was observed that sitting is also negatively significant correlated with $\mathrm{Hb}$ level which supports the previous literature that prolonged sitting may reduce the plasma fibrinogen, hemoglobin and red blood cells. ${ }^{25}$ Sedentary life style and excessive sitting is associated with the decline in the flow of blood to muscles, reduction of erythrocytes and their volume. It also leads to the muscles weakness which increases the chance of trauma to the joints and bones. ${ }^{26}$ Furthermore, in the current study no association has been found between walking and hemoglobin level. But, in a study conducted by Terink $\mathrm{R}$ et al. walking for a long time period may improve the $\mathrm{Hb}$ level. ${ }^{27}$

\section{CONCLUSION}

It was concluded that students who had perform vigorous and moderate physical activity have high hemoglobin concentration in blood. Students with longer duration of sitting had low hemoglobin concentration.

It is recommended to conduct further study to find cause and effect relationship of different level of physical activity on hemoglobin concentration (RCT).

\section{REFERENCES}

1. Caspersen CJ, Powell KE, Christenson GM. Physical activity, exercise, and physical fitness: definitions and distinctions for health-related research. Public Health Rep. 1985;100(2):126-31.

2. Makizako H, Liu-Ambrose T, Shimada H, Doi T, Park H, Tsutsumimoto $\mathrm{K}$, et al. Moderate-intensity physical activity, hippocampal volume, and memory in older adults with mild cognitive impairment. J. Gerontol. A Biol. Sci. Med. Sci. 2015;70(4):480-6.

3. Kohl 3rd HW, Craig CL, Lambert EV, Inoue S, Alkandari JR, Leetongin $\mathrm{G}$, et al. The pandemic of physical inactivity: global action for public health. Lancet Glob. Health. 2012;380(9838):294-305.

4. Kruk J. Health and economic costs of physical inactivity. Asian Pac. J. Cancer Prev. 2014;15(18):7499-503.

5. Croezen S, Visscher T, Ter Bogt N, Veling M, HavemanNies A. Skipping breakfast, alcohol consumption and physical inactivity as risk factors for overweight and obesity in adolescents: results of the E-MOVO project. Eur. J. Clin. Nutr. 2009;63(3):405-12.

6. Samir N, Mahmud S, Khuwaja AK. Prevalence of physical inactivity and barriers to physical activity among obese attendants at a community health-care center in Karachi, Pakistan. BMC Res. Notes. 2011;4(1):174. 
7. Arzu D, Tuzun EH, Eker L. Perceived barriers to physical activity in university students. J. Sci. Med. Sport. 2006;5(4):615.

8. McPhee JS, French DP, Jackson D, Nazroo J, Pendleton N, Degens $\mathrm{H}$. Physical activity in older age: perspectives for healthy ageing and frailty. Biogerontology. 2016;17(3):567-80.

9. Waxman A. WHO global strategy on diet, physical activity and health. FOOD NUTR. BULL. 2004;25(3):292-302.

10. Yu S, Yarnell J, Sweetnam P, Murray L. What level of physical activity protects against premature cardiovascular death? The Caerphilly study. Br. Heart J.. 2003;89(5):502-6.

11. Billett HH. Hemoglobin and hematocrit. Clinical Methods: The History, Physical, and Laboratory Examinations 3rd edition: Butterworths; 1990.

12. Haas JD, Brownlie IV T. Iron deficiency and reduced work capacity: a critical review of the research to determine a causal relationship. J. Nutr. 2001;131(2):676S-90S.

13. Mehta K. Prevalence of nutritional anaemia among college students and its correlation with their body mass index. Int J. Sci. Res. 2015;4(3):1882-6.

14. Dayi A, Acikgoz A, Guvendi G, Bayrak L, Ersoy B, Gur C, et al. Determination of factors affecting physical activity status of university students on a health sciences campus. Med. Sci. Monit. 2017;23:325.

15. Dinger MK, Behrens TK, Han JL. Validity and reliability of the International Physical Activity Questionnaire in college students. Am. J. Health. Promot. 2006;37(6):337-43.

16. Padmapriya K, Krishna P, Rasu T. Prevalence and patterns of physical activity among medical students in Bangalore, India. Electron. Physician. 2013;5(1):606.

17. Dabrowska-Galas M, Plinta R, Dabrowska J, SkrzypulecPlinta V. Physical activity in students of the Medical University of Silesia in Poland. Phys. Ther. 2013;93(3):38492.

18. Kumar H, Choi D-K. Hypoxia inducible factor pathway and physiological adaptation: a cell survival pathway? Mediators. Inflamm.. 2015;2015.

19. Mason SD. Hypoxia inducible factor-1alpha in the skeletal muscle during exercise and endurance training: UC San Diego; 2006.

20. Lindholm ME, Rundqvist H. Skeletal muscle hypoxiainducible factor-1 and exercise. Exp. Physiol. 2016;101(1):28-32.

21. Calbet JA, Lundby C, Koskolou M, Boushel R. Importance of hemoglobin concentration to exercise: acute manipulations. Respir. Physiol. Neurobiol. 2006;151(23):132-40.

22. Mohamady HM, Elsisi HF, Aneis YM. Impact of moderate intensity aerobic exercise on chemotherapy-induced anemia in elderly women with breast cancer: a randomized controlled clinical trial. J. Adv. Res. 2017;8(1):7-12.

23. Pourghardash F, Nikseresht A. Investigating the effect of regular aerobic activity on young females hematology. IIOABJ J. 2017;8(1):39-45.

24. Sazvar A, Mohammadi M, Nazem F, Farahpour N. The effect of morning aerobic exercise on some hematological parameters in young, active males. Iran. J. Public Health 2013;4(1).

25. Howard BJ, Fraser SF, Sethi P, Cerin E, Hamilton MT, Owen $\mathrm{N}$, et al. Impact on hemostatic parameters of interrupting sitting with intermittent activity. Med. Sci. Sports Exerc. 2013;45(7):1285-91.

26. Convertino VA, Bloomfield SA, Greenleaf JE. An overview of the issues: physiological effects of bed rest and restricted physical activity. Med. Sci. Sports Exerc. 1997;29(2):187-90.

27. Terink R, Ten Haaf D, Bongers C, Balvers M, Witkamp R, Mensink $M$, et al. Changes in iron metabolism during prolonged repeated walking exercise in middle-aged men and women. Eur. J. Appl. Physiol. 2018;118(11):2349-57.

Disclaimer: None to declare.

Conflict of Interest: None to declare.

Funding Sources: None to declare. 